\title{
The Effect of Priming a Thin Ideal on the Subsequent Perception of Conceptually Related Body Image Words
}

Conor T. McLennan

Cleveland State University, c.mclennan@csuohio.edu

Follow this and additional works at: https://engagedscholarship.csuohio.edu/clpsych_facpub

Part of the Cognition and Perception Commons, and the Health Psychology Commons

How does access to this work benefit you? Let us know!

\section{Publisher's Statement}

(c) 2011 Elsevier

\section{Recommended Citation}

Teresa A. Markis, Conor T. McLennan, The effect of priming a thin ideal on the subsequent perception of conceptually related body image words, Body Image, Volume 8, Issue 4, September 2011, Pages 423-426, ISSN 1740-1445, http://dx.doi.org/10.1016/j.bodyim.2011.05.001. (http://www.sciencedirect.com/ science/article/pii/S174014451100057X)

This Article is brought to you for free and open access by the Psychology Department at EngagedScholarship@CSU. It has been accepted for inclusion in Psychology Faculty Publications by an authorized administrator of EngagedScholarship@CSU. For more information, please contact library.es@csuohio.edu. 


\title{
Brief research report
}

\section{The effect of priming a thin ideal on the subsequent perception of conceptually related body image words}

\author{
Teresa A. Markis*, Conor T. McLennan \\ Department of Psychology, Cleveland State University, Cleveland, OH, United States
}

\section{Introduction}

Contemporary media promote a thin ideal standard that leads many females to feel badly about their weight and shape. Current standards of beauty emphasizing thinness are accepted by most women (Tiggeman, 2003). Furthermore, cognitive psychology suggests the existence of a schema in a given domain tends to produce biased processing of information relevant to that domain (Labarge, Cash, \& Brown, 1998; Vitousek \& Hollon, 1990). Appearance schemas are associated with levels of body dissatisfaction, which differ across females. Groesz, Levine, and Murnen (2002) found body dissatisfaction was increased for females after viewing thin media images, and this effect was strongest for those vulnerable to a thinness schema. Moreover, Yamamiya, Cash, Melnyk, Posavac, and Posavac (2005) study found even a brief exposure to thin ideal media images results in a more negative body image state among women, but showed females are not equally susceptible to the effects.

The goals of this study are to examine the effect of thin ideal priming on information processing and to gain knowledge about the role of body dissatisfaction. Body image dissatisfaction is of particular concern given a disturbance in the perception of body image is an essential feature of eating disorders (American Psychiatric Association, 2000). Body dissatisfaction accompanied by the thin ideal media could become a vicious cycle if after the development of an initial dissatisfaction, patients with an eating disorder paid extra attention to exactly the types of stimuli that led to the dissatisfaction in the first place. Indeed, there is evidence that patients selectively attend to stimuli related to their concerns, and this attentional component might be one way in which eating disorders are maintained (Cooper \& Fairburn, 1992).

A variant of the Stroop task (Stroop, 1935) has been adapted to provide a measure of selective processing for body image words in eating disorders. In the traditional Stroop task, participants see words in various colors and their task is to name the color of the font in which the word appears. When the words are color words that conflict with the required response (e.g., the word "blue" appears in red font, and their task is to say "red"), participants experience difficulty inhibiting their automatic reading response, which results in slowed processing or increased errors (e.g., saying blue instead of red). In the variant of the Stroop task relevant to our research, some of the words were body image words. Previous studies have found patients with eating disorders have difficulty inhibiting these words, and thus performing the task as efficiently as participants without eating disorders (Ben-Tovim, Walker, Fok, \& Yap, 1988; Dobson \& Dozois, 2004).

The study most closely related to the current study examined the role of thin ideal priming on the color naming of negative self-referent words with participants who were dissatisfied with their bodies, but not diagnosed with an eating disorder (Johansson, Lundh, \& Andersson, 2005). The authors found body dissatisfied participants were slower to color name self-referent words as a result of the thin ideal prime. We used Johansson et al.'s (2005) priming paradigm in this research study, but two crucial changes 
were made. First, our participants completed the body dissatisfaction questionnaire after priming and Stroop testing rather than before. Second, we used body-related words (thighs, fat), rather than performance and interpersonal threat words (fired, despised), keeping our study more closely related to previous studies of the Stroop effect in a clinical population.

This study is designed to examine the effect of thin ideal priming on the perception of body image words in participants without an eating disorder. It is hypothesized that in the group primed by the thin ideal there will be a relationship between body dissatisfaction and the extent to which participants' attend to the body image words. Specifically, a significant positive correlation is predicted between body dissatisfaction and the body effect of slower color naming times for the body words than the neutral words. This study intends to investigate one of the ways in which exposure to thin ideal media may have adverse effects on participants without an eating disorder. We are combining research on thin ideal media with a sample of non-clinical participants with the selective processing found in eating disorders. Our aim in comparing the effects of a thin ideal prime on the processing of body image words is to examine one of the ways in which exposure to the thin ideal in media has adverse effects on participants without an eating disorder.

\section{Specific Hypotheses}

Hypothesis 1 - overall reaction times (RTs) for participants in the thin ideal prime group were not expected to differ from overall RTs for participants in the control prime group. This main effect for prime type was not expected because the shoe primed group was expected to be primed for the shoe words, just as the thin ideal primed group was expected to be primed for the body words. Hypothesis 2 - participants' mean RTs for the three word types were predicted to differ significantly. Specifically, given that all participants were younger females, we predicted longer RTs to the body words than the shoe and neutral words. No RT difference was predicted between the shoe and neutral words. Hypothesis 3 - we predicted a significant positive correlation between body dissatisfaction and the body effect (i.e., longer mean RT for body image words than for neutral words), but only for participants in the thin ideal prime group and not for participants in the shoe prime group. In other words, we expected the degree to which participants would devote additional attentional resources to body words would increase as scores on the body dissatisfaction subscale increased, and we further expected this relationship would be modulated by prime type, such that the effect is present in participants who recently viewed thin female models with ideal bodies.

\section{Method}

\section{Participants}

Fifty-six female undergraduate students were recruited from Cleveland State University's participant pool. All participants were included and received credit for their participation. Participants were randomly assigned to one of the two priming conditions ( $n=28$ in each condition). Participants were told they were taking part in a study investigating contemporary mass media images.

\section{Stimulus Materials}

Pilot testing was carried out to choose the pictures used in the priming paradigm. Ten female undergraduate students were asked to rate 20 pictures of thin models from underwear advertisements (downloaded from the Internet) on how much they thought the picture depicts the thin ideal standard portrayed by the mass media on a scale of 1 (not at all) to 5 (very much). Pictures with ratings of 4 and above were chosen from the pilot study.

The priming paradigm consisted of 13 pictures of thin female models, mostly standing full body shots of four African American, eight Caucasian and two White European models from underwear advertisements (the thin ideal condition) and 13 pictures depicting gender-neutral shoes, shoes that are worn by both males and females (e.g., tennis shoes, hiking boots and crocs), taken from shoe advertisements (the control condition).

The Stroop task used three types of word stimuli: 12 neutral words (BED, LAMP, VASE, CHAIR, SHELF, BENCH, TOWEL, TABLE, CARPET, CURTAIN, BLANKET and WARDROBE), 12 words related to shoes (RUN, TOE, KICK, PUMP, SHOE, WALK, BOOTS, FOOTING, LEATHER, SNEAKER, MOCCASIN, and STOCKING), and 12 words related to body image (FAT, ARM, HIPS, FLESH, OBESE, PLUMP, WAIST, FIGURE, FLABBY, THIGHS, STOMACH, and BUTTOCKS). The word stimuli were matched on mean log frequency (Francis \& Kucera, 1982), familiarity (Nusbaum, Pisoni, \& Davis, 1984), mean number of letters per category, number of abstract and concrete words per category, and frequency weighted neighborhood density (Vitevich \& Luce, 1998). Each word was presented once in one of the four colors (red, blue, green, or yellow), producing a total of 36 trials for each participant. Four versions of the experiment were used to counterbalance 'word color' across participants.

\section{Apparatus}

The stimuli were presented with SuperLab 4.0.7b software. RTs in milliseconds were recorded using an SV-1 voice key from the onset of the presentation of the stimulus word until the onset of the participant's vocal response. A built-in microphone using Praat software, version 5.0.34, recorded participants' responses on the Stroop task.

\section{Procedure}

Participants were tested individually and were asked to give informed consent. Participants were randomly assigned to a priming condition, viewing either thin female models or pairs of shoes. Each of the 13 pictures in the priming task was shown for $30 \mathrm{~s}$. Participants viewing the thin female models were asked to rate to what extent each model was in accordance with their own perception of female body image on a 4 -point scale ( $1=$ not at all to $4=$ very much). There were two reasons for asking participants to rate the models in accordance with their own perception of female body image. First, this was done to ensure the participants were attending to the stimuli. Second, we wanted to examine the relationship between participants' ratings and their subsequent performance on the task, which is reported at the end of the Results section. In the same way, participants viewing advertisements for genderneutral shoes were asked to rate to what extent each pair of shoes is in accordance with their perception of nice looking shoes on the same 4-point scale.

During a subsequent block of trials, participants performed the Stroop task. In order to become familiar with the task, a practice session consisting of 12 trials was presented (color naming strings of X's, O's, and color words). Participants were instructed to ignore the content of the word and name the color in which the word was printed as quickly and accurately as possible. RTs to correct responses were compared across the three word type conditions. Participants were then asked to complete a written questionnaire that collected demographic information and measured body dissatisfaction using the body dissatisfaction subscale from the Eating Disorder Inventory (Garner, Olmstead, \& Polivy, 1983). The body dissatisfaction measure was used to assess the relationship of body 
Table 1

Means and standard deviations (SD) for Stroop reaction times.

\begin{tabular}{llll}
\hline Word type & Body prime, $n=28$ & Shoe prime, $n=28$ & Total, $N=56$ \\
\hline Body & $731.98(83.39)$ & $702.70(91.72)$ & $717.34(88.10)$ \\
Shoe & $707.38(91.01)$ & $681.83(75.50)$ & $694.60(83.85)$ \\
Neutral & $698.30(71.55)$ & $691.21(86.50)$ & $694.76(78.73)$ \\
Total & $712.55(66.57)$ & $691.91(77.92)$ & $702.23(72.56)$ \\
\hline
\end{tabular}

dissatisfaction to Stroop performance. Participants were debriefed and given credit for participation.

\section{Results}

The two priming groups did not differ $(p>.05)$ in age $(M=22.52$, $S D=6.06$ ), race, or grade level. To control for outliers, RTs below $200 \mathrm{~ms}$ and above $2000 \mathrm{~ms}$ were excluded for each participant (overall less than $1 \%$ of responses). Errors on the Stroop task did not exceed $10 \%$ for any of the participants.

A $2 \times 3$ mixed analysis of variance (ANOVA) with prime type a between participants factor and word type a within participants factor was performed on the RT data (see Table 1). Although the thin ideal prime group had numerically longer RTs $(M=712.55$, $S D=66.57)$ than the shoe prime group $(M=691.91, S D=77.92)$, the main effect for prime type was not significant $F(1,54)=1.136$, $p=.291, \eta^{2}=.021$, consistent with Hypothesis 1 . Overall, there was a main effect of word type, $F(2,108)=3.67, p=.029, \eta^{2}=.064$, consistent with Hypothesis 2. Participants' mean RTs were longer for body $(M=717.34, S D=88.10)$ than shoe $(M=694.60, S D=83.85)$ and neutral $(M=694.76, S D=78.73)$ words. In order to investigate the relationship between body effect and body dissatisfaction scores, correlation analyses were performed. A significant positive correlation was obtained in the thin ideal prime group, $r=.338, p=.039$ (effect size, Cohen's $d=0.43$ ), one-tailed, and not in the shoe prime group $r=.177, p=.184$, consistent with Hypothesis 3 .

In order to examine whether the body dissatisfaction responses were affected by participants' experiences in the study, we conducted a $t$-test directly comparing the body dissatisfaction scores for the thin prime group $(M=18.86, S D=10.33)$ to the shoe prime group $(M=17.14, S D=11.87)$. The results revealed no difference between the two groups $t(54)=0.577, p=.567$, demonstrating the body dissatisfaction responses were not affected by participants' experiences. If this were the case, then the thin ideal prime group should have had greater body dissatisfaction than the neutral prime group. Not only was the result not statistically significant, but the $t$ value was less than 1.0 and the means were remarkably similar.

Finally, participants' ratings of the models in the thin prime group were significantly correlated with body effect, $r=.318$, $p=.050$ (one-tailed). As participants' ratings reflected the models were more in line with their perception of a thin ideal, the greater the body effect found in the subsequent main task.

\section{Discussion}

The purpose of our study was to investigate the effect of thin ideal media and the role of body dissatisfaction on the perception of body image stimuli for participants without an eating disorder. Consistent with our predictions, we found a significant correlation between body dissatisfaction and body effect in the group primed with the thin models. Our results are consistent with previous research that found a Stroop interference effect for females who are high in body image concerns, specifically, appearance schema and body dissatisfaction (see Johansson et al., 2005; Labarge et al., 1998). Labarge postulates appearance schemas are activated by priming, thus leading to the Stroop effect. It is likely from the results of our study females high in body dissatisfaction exhibit this same kind of appearance schema, leading to the body effect.

A relationship between body dissatisfaction and reaction time to body image words could have many meanings. In theory, in women who have developed a thinness schema and sufficient body dissatisfaction, the ensuing exposure to thin ideal media could increase the risk for eating disorder pathology. Also, this attentional component may be one way in which eating disorders are maintained (Cooper \& Fairburn, 1992). Consequently, our results contribute to the body of literature investigating cognitive views of body image.

Two limitations to our study merit discussion. One, given the nature of our priming paradigm, we did not obtain a baseline measure of body dissatisfaction. It would be interesting in future research to focus on levels of high and low body image, both preand post-priming. Two, the shoe prime may have been too closely related to appearance to be completely neutral. However, genderneutral shoes were sufficiently neutral in the Johansson et al. study, and to the extent that shoes were not sufficiently neutral in the current study, this works against our finding a different pattern of results in the two prime groups. Nevertheless, we recommend use of a more neutral prime in future studies.

To our knowledge, no previous study has found evidence for the relationship between thin ideal priming and body dissatisfaction and the magnitude of the Stroop body effect with body related words in a non-eating disordered population. We think these findings warrant further investigation to carefully examine the extent to which body dissatisfaction and thin ideal standard in the media can affect processing in females, and the clinical importance such an effect may have for eating disordered patients.

\section{Acknowledgments}

This work represents portions of Teresa Markis' Master's thesis. We thank Kathie Judge and Richard Rakos for their feedback on this project as members of Teresa's thesis committee (CM was Chair). We also thank Alisa Maibauer, Maura Wilson, Jessica Newell, Jen Hrusovsky, Stacey Jacovetti, and Muji Abang for their help with data collection.

\section{References}

American Psychiatric Association. (2000). Diagnostic and statistical manual of mental disorders (4th ed.). Washington, DC: Author.

Ben-Tovim, D. I., Walker, M. K., Fok, D., \& Yap, E. (1988). An adaptation of the Stroop test for measuring shape and food concerns in eating disorders: A quantitative measure of psychopathology? International Journal of Eating Disorders, 8, 681-687.

Cooper, M. J., \& Fairburn, C. G. (1992). Selective processing of eating, weight and shape related words in patients with eating disorders and dieters. British Journal of Clinical Psychology, 31, 363-365.

Dobson, K. S., \& Dozois, D. J. A. (2004). Attentional biases in eating disorders: A meta-analytic review of Stroop performance. Clinical Psychology Review, 23. 1001-1022.

Francis, W. N., \& Kucera, H. (1982). Frequency analysis of English usage: Lexicon and grammar. New York: Houghton Mifflin.

Garner, D. M., Olmstead, M. P., \& Polivy, J. (1983). Development and validation of a multidimensional eating disorder inventory for anorexia nervosa and bulimia. International Journal of Eating Disorders, 2, 15-34.

Groesz, L. M, Levine, M. P., \& Murnen, S. K. (2002). The effect of experimental presentation of thin media images on body satisfaction: A meta-analytic review. International Journal of Eating Disorders, 31, 1-16.

Johansson, L., Lundh, L. G., \& Andersson, G. (2005). Attentional bias for negative self-words in young women: The role of thin ideal priming and body shape dissatisfaction. Personality and Individual Differences, 38, 723-733.

Labarge, A. S., Cash, T. F., \& Brown, T. A. (1998). Use of a modified Stroop task to examine appearance-schematic information processing in college women. Cognitive Therapy and Research, 22, 179-190.

Nusbaum, H. C., Pisoni, D. B., \& Davis, C. K. (1984). Sizing up the Hoosier Mental Lexicon: Measuring the familiarity of 20,000 words (Research on Speech Perception Progress Report No. 10, pp. 257-376).

Stroop, J. R. (1935). Studies of interference in serial verbal reactions. Journal of Experimental Psychology, 18, 643-662. 
Tiggeman, M. (2003). Media exposure, body dissatisfaction and disordered eating: Television and magazines are not the same!. European Eating Disorders Review, $11,418-430$

Vitevich, M. S., \& Luce, P. A. (1998). Phonotactics, phonological neighborhoods, and working memory in spoken word recognition. The Journal of the Acoustical Society of America, 104, 1758-11758.
Vitousek, K. B., \& Hollon, S. D. (1990). The investigation of schematic content and processing in eating disorders. Cognitive Therapy and Research, 14, 191214.

Yamamiya, Y., Cash, T. F., Melnyk, S. E., Posavac, H. D. \& Posavac, S. S. (2005).Women's exposure to thin-and-beautiful media images: Body image effects of media-ideal internalization and impact-reduction interventions. Body Image, 2, 74-80. 